\title{
Acute and 3-month effects of microcrystalline hydroxyapatite, calcium citrate and calcium carbonate on serum calcium and markers of bone turnover: a randomised controlled trial in postmenopausal women
}

\author{
Sarah M. Bristow*, Greg D. Gamble, Angela Stewart, Lauren Horne, Meaghan E. House, Opetaia Aati, \\ Borislav Mihov, Anne M. Horne and Ian R. Reid \\ Bone and Joint Research Group, Department of Medicine, University of Auckland, Private Bag 92 019, Auckland 1142, \\ New Zealand
}

(Submitted 18 February 2014 - Final revision received 22 July 2014 - Accepted 6 August 2014 - First published online 2 October 2014)

\section{Abstract}

Ca supplements are used for bone health; however, they have been associated with increased cardiovascular risk, which may relate to their acute effects on serum $\mathrm{Ca}$ concentrations. Microcrystalline hydroxyapatite $(\mathrm{MCH})$ could affect serum Ca concentrations less than conventional Ca supplements, but its effects on bone turnover are unclear. In the present study, we compared the acute and 3-month effects of $\mathrm{MCH}$ with conventional $\mathrm{Ca}$ supplements on concentrations of serum $\mathrm{Ca}$, phosphate, parathyroid hormone and bone turnover markers. We randomised 100 women (mean age 71 years) to $1 \mathrm{~g} / \mathrm{d}$ of $\mathrm{Ca}$ as citrate or carbonate (citrate-carbonate), one of two MCH preparations, or a placebo. Blood was sampled for $8 \mathrm{~h}$ after the first dose, and after 3 months of daily supplementation. To determine whether the acute effects changed over time, eight participants assigned to the citrate dose repeated $8 \mathrm{~h}$ of blood sampling at 3 months. There were no differences between the citrate and carbonate groups, or between the two MCH groups, so their results were pooled. The citrate-carbonate dose increased ionised and total $\mathrm{Ca}$ concentrations for up to $8 \mathrm{~h}$, and this was not diminished after $3 \mathrm{months}$. $\mathrm{MCH}$ increased ionised $\mathrm{Ca}$ concentrations less than the citrate-carbonate dose; however, it raised the concentrations of phosphate and the $\mathrm{Ca}$-phosphate product. The citrate-carbonate and $\mathrm{MCH}$ doses produced comparable decreases in bone resorption (measured as serum C-telopeptide (CTX)) over $8 \mathrm{~h}$ and bone turnover (CTX and procollagen type-I N-terminal propeptide) at 3 months. These findings suggest that Ca preparations, in general, produce repeated sustained increases in serum Ca concentrations after ingestion of each dose and that Ca supplements with smaller effects on serum Ca concentrations may have equivalent efficacy in suppressing bone turnover.

\section{Key words: Calcium supplements: Serum calcium: Bone turnover: Randomised trials}

Ca supplements have been widely used for treating or preventing osteoporosis, however, recent evidence suggests that they increase cardiovascular risk. In a meta-analysis of randomised controlled trials, Ca supplements, with or without vitamin D, significantly increased the risk of myocardial infarction $^{(1)}$. The findings of this meta-analysis have been questioned, primarily because cardiovascular events were not a primary endpoint in any of the included trials, and cardiovascular events were therefore not ascertained in a standardised manner. In contrast to supplemental $\mathrm{Ca}$, high intakes of dietary $\mathrm{Ca}$ do not appear to be associated with increased cardiovascular risk $^{(2-4)}$. A key difference between supplemental $\mathrm{Ca}$ and dietary $\mathrm{Ca}$ is their effects on serum Ca concentrations. While Ca supplements are taken in large doses that acutely raise serum $\mathrm{Ca}$ concentrations for at least $6 \mathrm{~h}$ following their ingestion ${ }^{(5,6)}$, Ca from the diet tends to be consumed in smaller amounts over a day, and even large amounts of dietary $\mathrm{Ca}$ have smaller effects on serum $\mathrm{Ca}$ concentrations ${ }^{(7)}$. It may be the elevation in serum Ca concentrations, after ingestion of Ca supplements, that underlies the increase in cardiovascular risk. In observational studies, higher serum $\mathrm{Ca}$ concentrations within the normal range have been associated with increased cardiovascular risk $^{(8-10)}$. There are several possible mechanisms by which increased serum $\mathrm{Ca}$ concentrations could influence cardiovascular risk, perhaps involving the activity of vascular smooth muscle cells or endothelial cells, or by influencing blood coagulation ${ }^{(11)}$.

However, Ca remains an essential nutrient for bone health. Some observational studies have shown lower bone mineral density and an increased risk of fracture among those with the lowest intakes of $\mathrm{Ca}^{(12,13)}$. In light of the adverse

Abbreviations: CTX, C-telopeptide; MCH, microcrystalline hydroxyapatite; PINP, procollagen type-I N-terminal propeptide; PTH, parathyroid hormone.

*Corresponding author: S. M. Bristow, fax +649373 7677, email s.bristow@auckland.ac.nz 
cardiovascular risks associated with Ca supplementation, it has been recommended that individuals meet the recommended intakes of $\mathrm{Ca}$ through diet alone, or that smaller doses of supplements are used ${ }^{(14,15)}$. Although dietary intakes of $\mathrm{Ca}$ often fall below the recommended levels ${ }^{(16-18)}$, it would be theoretically possible for most people to meet these intakes through dietary sources alone. However, there are others, such as the elderly or those who are unable to or choose not to consume dairy products, who may be at risk of inadequate intakes ${ }^{(19,20)}$, and for whom supplementation may be recommended. Therefore, there exists a need for a safer form of supplemental Ca. Microcrystalline hydroxyapatite $(\mathrm{MCH})$, derived from bovine bone, contains $\mathrm{Ca}$ and phosphate in the form of hydroxyapatite, as well as collagenous and non-collagenous bone proteins. $\mathrm{MCH}$ has previously been shown to have a smaller effect on serum Ca concentrations than conventional Ca supplements $4 \mathrm{~h}$ postingestion $^{(21)}$. MCH could potentially provide a safer form of supplemental $\mathrm{Ca}$ to the cardiovascular system than conventional supplements. However, documentation of the acute and medium-term effects of different types of Ca supplements on serum Ca concentrations and related variables in carefully conducted randomised trials is scant, particularly using currently accepted markers of bone turnover.

To evaluate $\mathrm{MCH}$ as a form of supplemental $\mathrm{Ca}$, we compared its acute effects on serum Ca concentrations with those of conventional $\mathrm{Ca}$ supplements, and assessed their medium-term effects on bone turnover. There are a number of ways in which $\mathrm{MCH}$ preparations may be produced with respect to the degree of protein hydrolysis and granule size, so, as a secondary aim, we determined whether differences in these variables influenced the effects on serum Ca concentrations or bone turnover. Finally, we examined the duration of the elevation in serum $\mathrm{Ca}$ concentrations following the ingestion of a Ca supplement, as few trials have continued beyond $4-6 \mathrm{~h}$, and determined whether these acute effects were attenuated with long-term use.

\section{Methods}

\section{Participants}

The present study was a trial of 100 women, at least 5 years postmenopause. We recruited women from those who had volunteered for other osteoporosis studies, but had been ineligible for those studies because they had normal bone density. We excluded women with a history of CVD, a 5-year cardiovascular risk of $>15 \%$; or a major ongoing systemic illness; or if they had taken any medication known to affect $\mathrm{Ca}$ concentrations or bone metabolism in the past year, or were taking $>2000 \mathrm{IU} / \mathrm{d}(50 \mu \mathrm{g} / \mathrm{d})$ of vitamin D. Participants who regularly used more than $100 \mathrm{mg} / \mathrm{d}$ of $\mathrm{Ca}$ supplements required a 6-month withdrawal period before entering the study. We reviewed the medical history questionnaires of approximately 1000 women, of whom 415 met the inclusion and exclusion criteria and were invited to participate. Women who expressed interest in participating were asked to complete a self-administered medical history questionnaire, which was reviewed by study staff to ensure they still met these criteria. The flow of the participants through the study is presented in Fig. 1. Of the participants, three with phlebotomy difficulties withdrew after randomisation but before receiving their first dose of treatment. These women did not contribute data to the study, and by convention, those participants who were randomised but who withdrew before receiving the study intervention were excluded from the intention-to-treat analysis.

\section{Study design}

Participants were randomised to the treatment with Ca $(1 \mathrm{~g} / \mathrm{d})$ as citrate or carbonate (citrate-carbonate), one of two $\mathrm{MCH}$ preparations, or a Ca-free placebo, for 3 months. A $1 \mathrm{~g}$ dose of Ca was studied as this has been most commonly studied in relation to fracture and cardiovascular risk ${ }^{(1,22)}$. For the present study, two MCH preparations (denoted MCHA and MCHB) were supplied by Waitaki Biosciences. The MCHA preparation had a smaller particle size and a greater degree of protein hydrolysis compared with MCHB. New Zealand cattle are free of BSE. Calcium carbonate (Kirsch Pharma) and calcium citrate (Jost Chemical Company) were purchased from Hawkins Watts. All four treatments and placebo were given as powders encapsulated in identical gelatin capsules. Each capsule contained $125 \mathrm{mg}$ Ca or placebo. Triplicate samples of each of the four treatments and placebo were analysed to verify $\mathrm{Ca}$ content. Treatment was randomly assigned using a computergenerated variable-block randomisation schedule prepared by staff not in contact with participants. Participants were blinded to the treatment that they received for the duration of the study. Study staff were not blinded throughout the study. This was to allow further measurements to be carried out on only those participants allocated to calcium citrate and placebo (data to be presented elsewhere).

On day 1 of the study, participants attended an $8 \mathrm{~h}$ session at our research clinic after an overnight fast. A baseline blood sample was collected between 07.00 and 09.00 hours, after which participants immediately received the first dose of their allocated treatment with water. Further blood samples were collected 2, 4, 6 and $8 \mathrm{~h}$ after the treatment was ingested. To permit the effects of the allocated treatment to be examined in isolation, participants were asked to consume only the standardised low-Ca meals provided during the $8 \mathrm{~h}$ period. A light breakfast (peaches in juice and toast with margarine and jam, marmalade or honey) was provided immediately after the treatment was ingested; a light lunch (fruit salad in juice and bread with margarine and jam, honey, marmalade or peanut butter) was provided at $4 \mathrm{~h}$, followed by an optional snack (plain biscuits and decaffeinated tea) at $6 \mathrm{~h}$. Meals were provided after the blood sampling was completed for that time point. The breakfast meal provided an additional $74 \mathrm{mg} \mathrm{Ca}$, the lunch $74-80 \mathrm{mg} \mathrm{Ca}$, and the snack $6 \mathrm{mg} \mathrm{Ca}$, by calculation. Water and non-caffeinated tea without milk were allowed ad libitum throughout the day.

After day 1, participants were instructed to take their treatment at home in two divided doses, with their morning and evening meals. Midway through the study, participants 


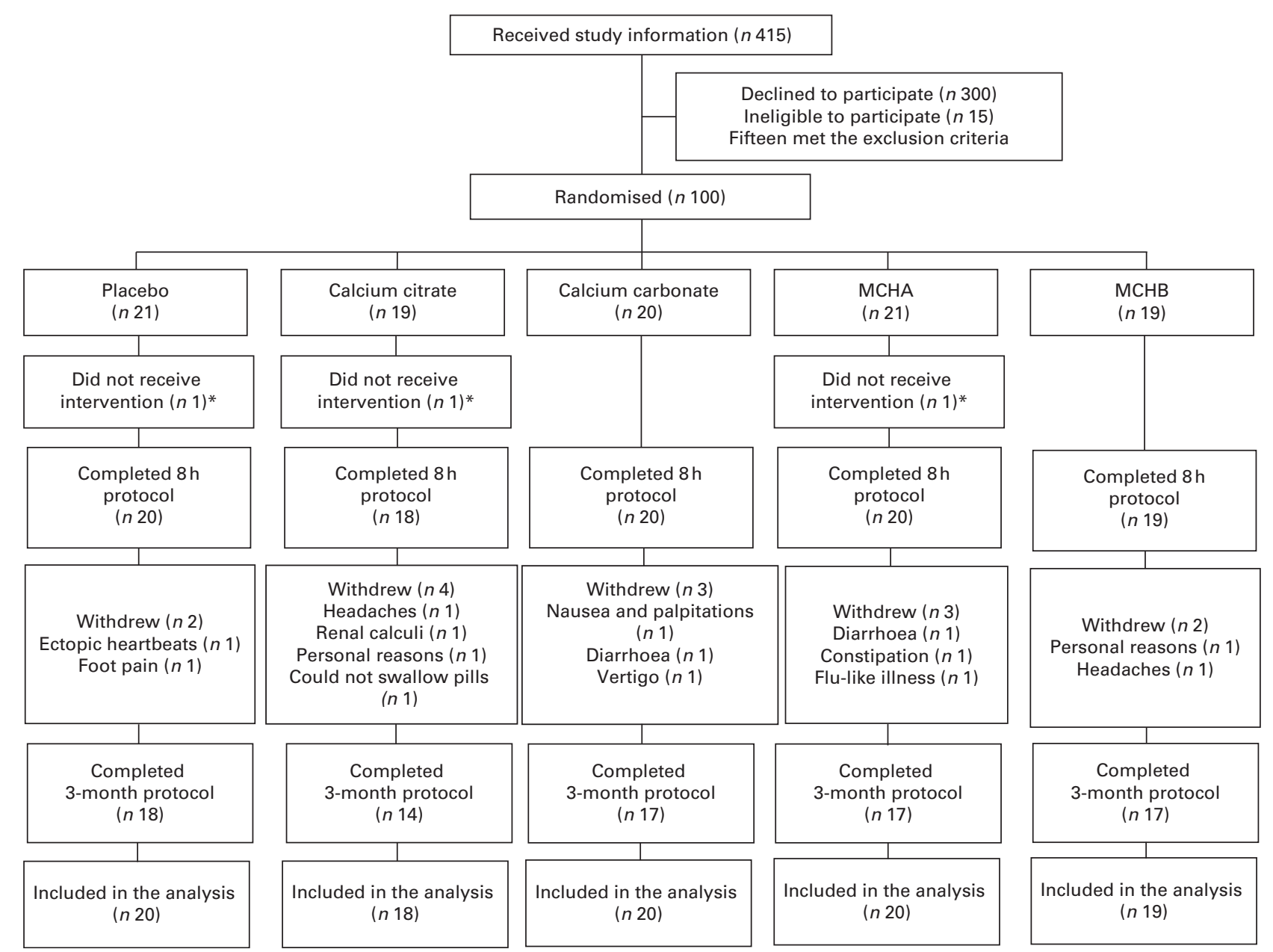

Fig. 1. Flow of the participants through the study. $\mathrm{MCH}$, microcrystalline hydroxyapatite. ${ }^{*}$ Three participants were unable to be cannulated. These participants did not receive the study intervention, did not contribute data to the study and were not included in the analysis.

were telephoned to encourage compliance. After 3 months, participants returned to our clinic having taken their final dose of treatment the evening before, and a final fasting blood sample was collected. As it is unknown whether the acute effects of conventional $\mathrm{Ca}$ supplements on serum $\mathrm{Ca}$ concentrations are different after long-term use, we invited participants allocated to calcium citrate to repeat the $8 \mathrm{~h}$ sampling protocol as carried out on day 1 . The present study was conducted according to the guidelines laid down in the Declaration of Helsinki, and all procedures involving human participants were approved by the New Zealand Northern Regional X Ethics Committee. Written informed consent was obtained from all participants. The present study was registered with the Australia New Zealand Clinical Trials registry (ACTRN12611000232932).

\section{Measurements}

Ionised Ca concentration was measured on anaerobically handled specimens using an ABL800 FLEX blood gas analyser (Radiometer) within $60 \mathrm{~min}$ of collection. The samples for the measurement of total $\mathrm{Ca}$ and phosphate concentrations were batch-analysed at the end of each $8 \mathrm{~h}$ session using a Cobas modular analyser (Roche Diagnostics). The samples for the measurement of parathyroid hormone (PTH) and bone turnover markers were stored at $-70^{\circ} \mathrm{C}$ and batch-analysed at the completion of the study. Roche autoanalysers were used for the measurement of PTH, serum procollagen type-I N-terminal propeptide (PINP) and serum C-telopeptide (CTX) concentrations (Roche Diagnostics). Baseline 25-hydroxyvitamin D concentration was measured using the API 400 LC/MS/MS System (ABSciex).

Body weight was measured using electronic scales, and height using a Harpenden stadiometer (Holtain). Dietary Ca intake was assessed using a validated $\mathrm{FFQ}^{(23)}$. Compliance was assessed at the final visit by capsule count and calculated as the number of capsules taken as a percentage of the number that should have been taken.

\section{Statistical analyses}

The present study was adequately powered (80\%) at the 5\% significance level to detect a between-group difference in either of the bone turnover markers of at least one standard deviation. Effects of this size have previously been observed with Ca supplementation and are likely to be of clinical significance. 
Data were analysed on a modified intention-to-treat basis (three participants who were randomised but who did not commence the study treatment were excluded) using a mixed-model approach to repeated measures (Proc Mixed, SAS version 9.2; SAS Institute, Inc.). The assumptions of normality and homogeneity of variance were met, and all models were inspected for adequacy of fit. Exact methods were employed where appropriate. The change from baseline was the dependent variable and baseline value of the appropriate variable was included as a covariate (ANCOVA). Significant main (time or treatment allocation) and interaction effects (time $\times$ treatment allocation) were further explored using the method of Tukey to construct honestly significant differences; however, since these comparisons were pre-planned, the pairwise $P$ values were not adjusted for multiplicity. The areas under the ionised $\mathrm{Ca}$, total $\mathrm{Ca}$ or phosphate concentrations over time functions (AUC) were calculated using a trapezoidal method and provided the dependent variable as indicated.

All tests were two-tailed and $P<0.05$ was considered significant.

\section{Results}

The baseline clinical and biochemical characteristics of participants are presented in Table 1 . The groups were comparable in all indices at baseline. Over the 3-month study period, $85 \%$ of participants took $80 \%$ or more of their allocated capsules. Median compliance was not different between the groups $(P=0 \cdot 10)$.

\section{Acute effects on serum calcium and phosphate concentrations}

Changes in the concentrations of serum ionised Ca (ANCOVA, treatment $\times$ time interaction, $P=0.002$ ), total Ca (treatment $\times$ time interaction, $P=0.0001)$ and phosphate (treatment $\times$ time interaction, $P<0.0001$ ) were different among the five groups. Changes in the concentrations of ionised $\mathrm{Ca}$, total $\mathrm{Ca}$ and phosphate were not different at any time point between the calcium citrate and calcium carbonate groups (all $P>0 \cdot 20$ ), or between the MCHA and MCHB groups (all $P>0.34$, expect for changes in ionised $\mathrm{Ca}$ concentrations at $6 \mathrm{~h}, P=0 \cdot 07$ ). To allow for comparison between conventional Ca supplements (citrate and carbonate) and $\mathrm{MCH}$, the results from these groups were pooled for subsequent analyses.

Ionised Ca concentrations increased in the citrate-carbonate and $\mathrm{MCH}$ groups compared with the control group (Fig. 2). Over 8 h, fifteen participants in the citrate-carbonate group, four in the $\mathrm{MCH}$ group and none in the placebo group had an ionised $\mathrm{Ca}$ measurement above the normal range $(>1.30 \mathrm{mmol} / \mathrm{l})$ at one or more time points. The change in ionised $\mathrm{Ca}$ concentrations was more positive in the citratecarbonate group than in the MCH group, and the corresponding AUC was greater in the citrate-carbonate group than in the $\mathrm{MCH}$ group. Total $\mathrm{Ca}$ concentrations also increased in both the citrate-carbonate and $\mathrm{MCH}$ groups compared with the control group (Fig. 2). The increase in total Ca concentrations was slightly greater in the citrate-carbonate group than in the MCH group; however, the AUC for total Ca concentrations was not different between those two groups. Ionised $\mathrm{Ca}$ and total $\mathrm{Ca}$ concentrations remained increased from baseline $8 \mathrm{~h}$ after the dose was ingested in the citrate-carbonate group $(P<0 \cdot 0001)$ and $\mathrm{MCH}$ group $(P<0 \cdot 01)$.

Serum phosphate concentration was increased in the $\mathrm{MCH}$ group compared with the citrate-carbonate and control groups (Fig. 3). The change in phosphate concentration was not different between the citrate-carbonate and control groups, except at $6 \mathrm{~h}$. Phosphate concentration remained increased from baseline at $8 \mathrm{~h}$ in the $\mathrm{MCH}$ group

Table 1. Baseline clinical and biochemical characteristics of participants (Mean values and standard deviations)

\begin{tabular}{|c|c|c|c|c|c|c|c|c|c|c|c|c|}
\hline & \multicolumn{2}{|c|}{$\begin{array}{c}\text { Calcium citrate } \\
\quad(n 18)\end{array}$} & \multicolumn{2}{|c|}{$\begin{array}{c}\text { Calcium } \\
\text { carbonate }(n \text { 20) }\end{array}$} & \multicolumn{2}{|c|}{$\mathrm{MCHA}(n 20)$} & \multicolumn{2}{|c|}{$\mathrm{MCHB}(n 19)$} & \multicolumn{2}{|c|}{ Control (n 20) } & \multicolumn{2}{|c|}{ Total $(n 97)$} \\
\hline & Mean & SD & Mean & SD & Mean & SD & Mean & SD & Mean & SD & Mean & SD \\
\hline \multicolumn{13}{|l|}{ Clinical characteristics } \\
\hline Age (years) & 72 & 6 & 70 & 4 & 71 & 5 & 73 & 6 & 70 & 3 & 71 & 5 \\
\hline Weight $(\mathrm{kg})$ & $72 \cdot 1$ & $10 \cdot 5$ & $76 \cdot 5$ & 14.9 & $72 \cdot 4$ & $15 \cdot 3$ & $76 \cdot 4$ & $12 \cdot 1$ & 71.5 & $9 \cdot 2$ & $73 \cdot 8$ & $12 \cdot 6$ \\
\hline Height (m) & 1.61 & 0.06 & 1.64 & 0.06 & $1 \cdot 61$ & 0.07 & 1.60 & 0.06 & 1.63 & 0.06 & 1.62 & 0.06 \\
\hline BMI $\left(\mathrm{kg} / \mathrm{m}^{2}\right)$ & $27 \cdot 6$ & 3.5 & $28 \cdot 3$ & $4 \cdot 6$ & $27 \cdot 9$ & $6 \cdot 0$ & 29.7 & 4.9 & $27 \cdot 0$ & 4.6 & $28 \cdot 1$ & 4.8 \\
\hline$<25(\%)$ & \multicolumn{2}{|c|}{28} & \multicolumn{2}{|c|}{25} & \multicolumn{2}{|c|}{40} & \multicolumn{2}{|c|}{16} & \multicolumn{2}{|c|}{37} & \multicolumn{2}{|c|}{29} \\
\hline $25-30(\%)$ & \multirow{2}{*}{\multicolumn{2}{|c|}{$\begin{array}{l}50 \\
2 ?\end{array}$}} & \multicolumn{2}{|c|}{$\begin{array}{l}35 \\
40\end{array}$} & \multicolumn{2}{|c|}{45} & \multicolumn{2}{|c|}{37} & \multicolumn{2}{|c|}{32} & \multicolumn{2}{|c|}{40} \\
\hline$>30(\%)$ & & & \multicolumn{2}{|c|}{40} & \multicolumn{2}{|c|}{15} & \multicolumn{2}{|c|}{47} & \multicolumn{2}{|c|}{32} & \multicolumn{2}{|c|}{31} \\
\hline Dietary Ca (mg/d) & 970 & 380 & 810 & 320 & 890 & 420 & 780 & 400 & 900 & 500 & 870 & 410 \\
\hline \multicolumn{13}{|c|}{ Biochemical characteristics } \\
\hline 25(OH)D (nmol/l) & 80 & 20 & 71 & 23 & 69 & 18 & 70 & 21 & 68 & 18 & 71 & 20 \\
\hline Ionised Ca (mmol/l) & 1.21 & 0.03 & 1.23 & 0.06 & $1 \cdot 21$ & 0.03 & 1.22 & 0.06 & 1.21 & 0.03 & 1.22 & 0.04 \\
\hline Total $\mathrm{Ca}(\mathrm{mmol} / \mathrm{l})^{\star}$ & $2 \cdot 19$ & 0.07 & $2 \cdot 18$ & 0.08 & $2 \cdot 16$ & 0.07 & $2 \cdot 16$ & 0.09 & $2 \cdot 16$ & 0.09 & $2 \cdot 17$ & 0.09 \\
\hline Phosphate (mmol/l) & 1.06 & 0.13 & $1 \cdot 10$ & 0.20 & $1 \cdot 12$ & $0 \cdot 11$ & $1 \cdot 14$ & 0.09 & $1 \cdot 11$ & 0.03 & $1 \cdot 11$ & 0.14 \\
\hline PTH (pmol/l) & 4.6 & $1 \cdot 2$ & $4 \cdot 0$ & 1.3 & 4.8 & $2 \cdot 2$ & $4 \cdot 3$ & $1 \cdot 2$ & $4 \cdot 3$ & $1 \cdot 2$ & 4.4 & 1.5 \\
\hline CTX $(\mu \mathrm{g} / \mathrm{l})$ & 0.38 & 0.11 & 0.37 & 0.15 & 0.39 & 0.15 & 0.41 & $0 \cdot 18$ & 0.34 & 0.14 & 0.38 & 0.15 \\
\hline PINP $(\mu \mathrm{g} / \mathrm{l})$ & $45 \cdot 1$ & $14 \cdot 0$ & $46 \cdot 5$ & $19 \cdot 1$ & $44 \cdot 8$ & $15 \cdot 2$ & $52 \cdot 4$ & $28 \cdot 7$ & $43 \cdot 8$ & $15 \cdot 3$ & $46 \cdot 8$ & $19 \cdot 3$ \\
\hline
\end{tabular}

$\mathrm{MCH}$, microcrystalline hydroxyapatite; 25(OH)D, 25-hydroxyvitamin D; PTH, parathyroid hormone; CTX, C-telopeptide; PINP, procollagen type-I N-terminal propeptide. ${ }^{\star}$ Corrected for albumin. 

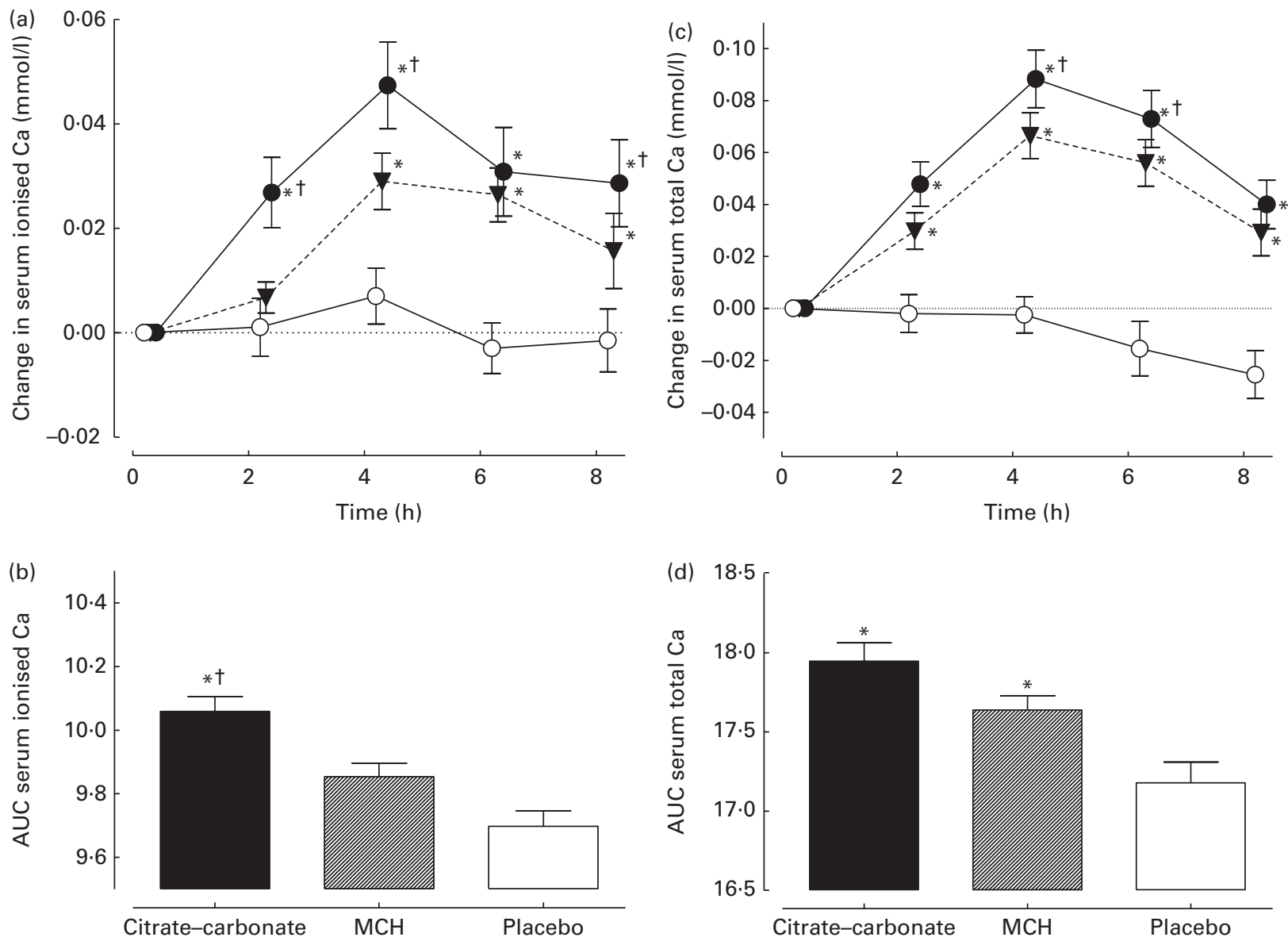

Fig. 2. (a) Changes in serum ionised calcium concentration, (b) AUC of serum ionised calcium, (c) changes in serum total calcium concentration and (d) AUC of total calcium over $8 \mathrm{~h}$ after the ingestion $1 \mathrm{~g}$ calcium as citrate or carbonate (citrate-carbonate (-); $n$ 38), microcrystalline hydroxyapatite (MCH (- $\mathbf{-}$-); $n 39)$ or a placebo containing no calcium (control $(-0)$; $n$ 20). Values are means, with their standard errors represented by vertical bars. Changes in ionised calcium (ANCOVA, treatment $\times$ time interaction, $P=0.0003$ ) and total calcium (treatment $\times$ time interaction, $P<0.0001$ ) concentrations differed significantly between the three groups. * Mean value was significantly different from that of the control group $(P<0.05)$. $†$ Mean value was significantly different from that of the MCH group $(P<0.05)$.

$(P<0 \cdot 0001)$. The concentration of the $\mathrm{Ca}-$ phosphate product (ionised $\mathrm{Ca} \times$ phosphate) was increased in the $\mathrm{MCH}$ and citrate-carbonate groups relative to the control group, and the increase was greater in the $\mathrm{MCH}$ group (Fig. 3).

After 3 months of supplementation, fasting ionised $\mathrm{Ca}$ concentration was increased from baseline in the citratecarbonate group by $0.01 \mathrm{mmol} / 1(P=0.006)$ and fasting total Ca concentration was lower than baseline in the control group by $0.03 \mathrm{mmol} / \mathrm{l}(P=0.02)$. Fasting phosphate concentration was lower than baseline at 3 months in the $\mathrm{MCH}$ group by $0.04 \mathrm{mmol} / 1(P=0.01)$. In the eight participants allocated to calcium citrate who repeated the $8 \mathrm{~h}$ of blood sampling at 3 months, the changes in ionised and total $\mathrm{Ca}$ concentrations were similar to those observed at baseline (Fig. 4).

\section{Acute and long-term effects on parathyroid hormone and markers of bone turnover}

Changes up to 3 months in the concentrations of PTH (ANCOVA, treatment $\times$ time interaction, $P=0 \cdot 04$ ), CTX (treatment $\times$ time interaction, $P=0.0006$ ) and PINP (treatment $\times$ time interaction, $P=0.002)$ were different among the five groups. Changes in the concentrations of PTH, CTX and PINP were not different between the citrate and carbonate groups $(P>0 \cdot 25)$ or between the MCHA and MCHB groups (all $P>0 \cdot 13$ ) at any time point. The results from these groups were therefore pooled as above.

PTH concentration declined over the $8 \mathrm{~h}$ after the first dose of citrate-carbonate or $\mathrm{MCH}$ compared with the control group, and the reduction in PTH concentration was greater in the citrate-carbonate group than in the $\mathrm{MCH}$ group (Fig. 5). CTX concentration declined from baseline in the control group from 2 to $8 \mathrm{~h}$ (all $P<0.0001$ ). There was a further reduction in the concentration of CTX in the citrate-carbonate and $\mathrm{MCH}$ groups compared with the control group (Fig. 5). The change in the concentration of CTX over $8 \mathrm{~h}$ was not different between the citrate-carbonate and $\mathrm{MCH}$ groups at any time point. The concentration of PINP increased from baseline in all groups at $8 \mathrm{~h}($ all $P<0 \cdot 04)$, and was not different between the groups.

After 3 months, PTH concentration was slightly but significantly lower in the citrate-carbonate and $\mathrm{MCH}$ groups relative to the control group (Fig. 5). Both CTX and PINP concentrations were significantly lower than those at baseline in the citrate-carbonate and $\mathrm{MCH}$ groups compared with the control 

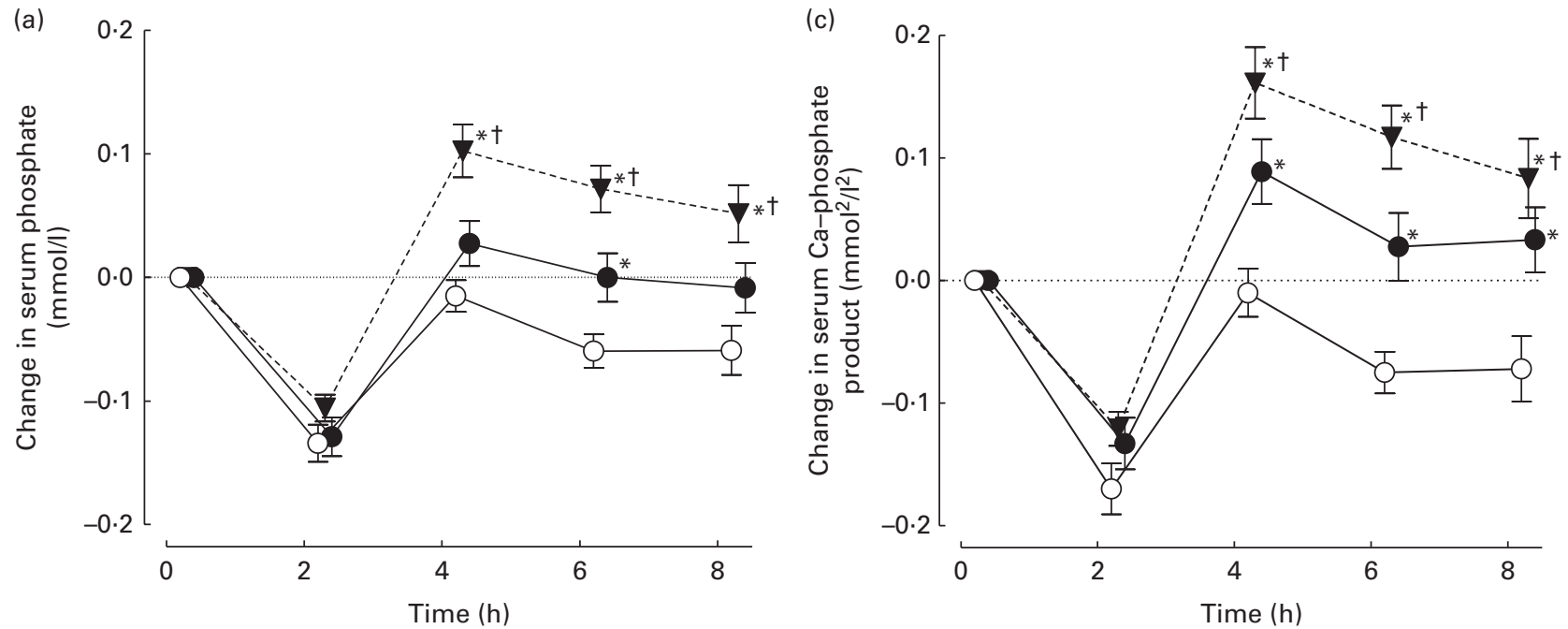

(b)

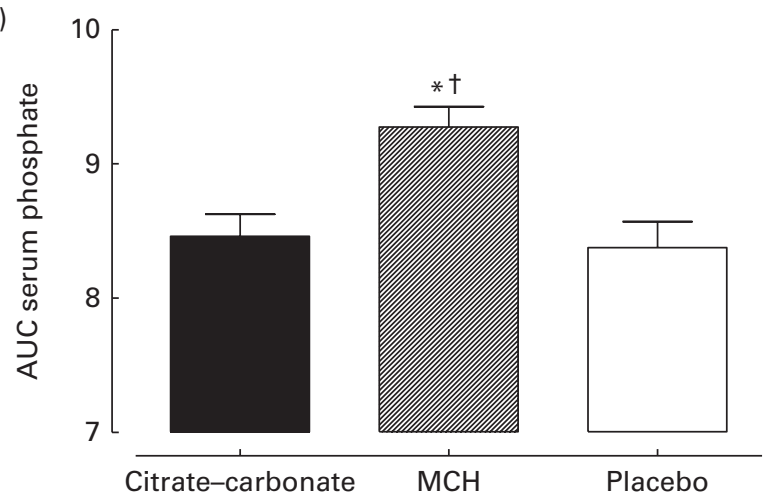

Fig. 3. (a) Changes in serum phosphate concentration, (b) AUC of serum phosphate and (c) change in serum calcium-phosphate product concentration, over $8 \mathrm{~h}$ after the ingestion $1 \mathrm{~g}$ calcium as citrate or carbonate (citrate-carbonate $(--) ; n 38)$, microcrystalline hydroxyapatite (MCH (- - -); $n 39)$ or a placebo containing no calcium (control (-o-); $n$ 20). Values are means, with their standard errors represented by vertical bars. Changes in phosphate (ANCOVA, treatment $\times$ time interaction, $P<0.0001)$ and calcium-phosphate product $(P<0.0001)$ concentrations differed significantly between the three groups. ${ }^{*}$ Mean value was significantly different from that of the control group $(P<0.05)$. † Mean value was significantly different from that of the citrate-carbonate group $(P<0.05)$.

group. There were no differences in the reduction in the concentrations of PTH, CTX and PINP at 3 months between the citrate-carbonate and $\mathrm{MCH}$ groups.

\section{Discussion}

In the present study, the ingestion of $1 \mathrm{~g} \mathrm{Ca}$ as citrate, carbonate or $\mathrm{MCH}$ resulted in an acute and sustained elevation of serum Ca concentrations and suppression of bone resorption. In addition, after 3 months of supplementation, there was a reduction in bone turnover (reflected in both CTX and PINP levels). Ingestion of $\mathrm{MCH}$ resulted in a smaller increase in serum $\mathrm{Ca}$ concentrations than the intake of conventional citrate and carbonate supplements, but increased the concentrations of phosphate and the $\mathrm{Ca}-$ phosphate product.

Ionised and total $\mathrm{Ca}$ concentrations remained elevated above baseline and the control group $8 \mathrm{~h}$ after a $1 \mathrm{~g}$ dose of $\mathrm{Ca}$. Some studies have reported elevations in serum Ca concentrations up to $6 \mathrm{~h}$ after an oral dose $e^{(7,24,25)}$, but few have continued beyond this time point. In postmenopausal women, serum $\mathrm{Ca}$ concentration was significantly greater than the control 3-12 $\mathrm{h}$ after the ingestion of calcium carbonate and $1-9 \mathrm{~h}$ after the ingestion of calcium citrate ${ }^{(6)}$. Similarly, in postmenopausal women, an evening dose of calcium carbonate or citrate raised serum $\mathrm{Ca}$ concentrations for at least $12 \mathrm{~h}^{(26)}$. Furthermore, in the present study, the serum $\mathrm{Ca}$ excursion was not different when calcium citrate was taken at baseline, or after 3 months of continuous supplementation. In longitudinal studies ${ }^{(8)}$, differences in serum $\mathrm{Ca}$ concentrations of the magnitude observed in the present study are associated with a $17 \%$ increase in cardiovascular risk, very similar to that found in the trials of $\mathrm{Ca}$ supplementation ${ }^{(27)}$.

Few studies have compared the acute effects of MCH with other forms of $\mathrm{Ca}$. Consistent with our findings, these studies have demonstrated smaller increases in serum Ca concentrations and/or reductions in PTH concentrations following the ingestion of $\mathrm{MCH}$ compared with other $\mathrm{Ca}$ salts ${ }^{(21,24,28)}$. The smaller rise in serum $\mathrm{Ca}$ concentrations following the ingestion of $\mathrm{MCH}$ may have been due to a lower bioavailability of $\mathrm{Ca}$. This was suggested by the smaller AUC of ionised $\mathrm{Ca}$ following the ingestion of $\mathrm{MCH}$ compared with citrate-carbonate intake. Alternatively, $\mathrm{Ca}$ may have been more slowly absorbed from MCH because of slow dissolution 

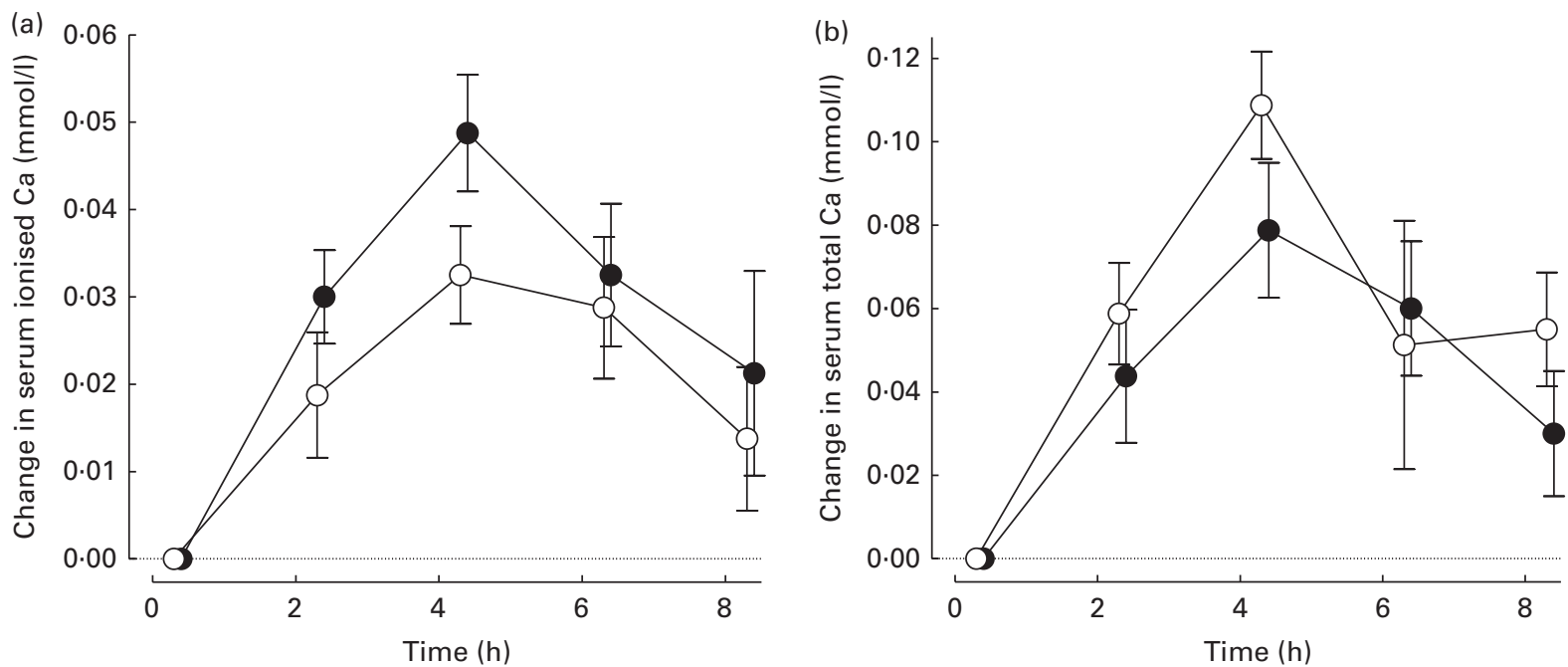

Fig. 4. Changes in serum (a) ionised calcium and (b) total calcium concentrations, over $8 \mathrm{~h}$ after the ingestion $1 \mathrm{~g}$ calcium as citrate at baseline (-) or $1 \mathrm{~g}$ calcium as citrate after 3 months (-o-) of continuous supplementation $(n 8)$. Values are means, with their standard errors represented by vertical bars. Changes in ionised calcium (ANCOVA, treatment $\times$ time interaction, $P=0.62)$ and total calcium $(P=0.61)$ concentrations were not different between the two time points.

of the hydroxyapatite crystal in the gastrointestinal tract, and the need for hydrolysis of the protein matrix. However, it should be noted that $\mathrm{MCH}$ was comparably effective in reducing bone turnover, so it does achieve the same therapeutic effect with a lesser increase in serum Ca concentrations. In contrast to the significantly smaller effect of $\mathrm{MCH}$ on ionised $\mathrm{Ca}$ concentrations, the differences between the groups for total $\mathrm{Ca}$ concentrations were less pronounced. Increased serum phosphate concentrations might explain the smaller effect of $\mathrm{MCH}$ on ionised $v$. total $\mathrm{Ca}$ concentrations, since Ca complexes with phosphate.

We found no differences between the citrate and carbonate groups, or between the $\mathrm{MCH}$ groups. Calcium citrate is more soluble than carbonate, and has been suggested to be more absorbable and/or result in a larger increase in serum Ca concentrations ${ }^{(26,29,30)}$, although others have found no difference ${ }^{(5,6,24)}$. Solubility plays a limited role in determining $\mathrm{Ca}$ absorption, when $\mathrm{Ca}$ is administered with a meal to healthy people ${ }^{(31,32)}$. Differences between calcium carbonate and citrate in some trials might reflect differences in the physical form in which they were administered (e.g. powder $v$. tablet $)^{(33)}$. In the present study, all preparations were administered as identical encapsulated powders. Similarly, the more finely processed $\mathrm{MCH}$ preparation would be expected to be more rapidly absorbed than the less finely processed preparation, due to the greater surface area of the smaller particles, but this was not the observed outcome.

PTH exhibits a marked diurnal rhythm ${ }^{(34)}$, as do markers of bone resorption, such as $\mathrm{CTX}^{(35-37)}$. Accordingly, we observed significant changes in the concentrations of PTH and CTX in the control group of the present study during the $8 \mathrm{~h}$ period; these changes were very similar to those previously reported for $\mathrm{PTH}^{(34)}$ and $\mathrm{CTX}^{(37)}$. The citratecarbonate and $\mathrm{MCH}$ preparations further reduced CTX concentrations over $8 \mathrm{~h}$ compared with the control. Markers of bone formation, such as PINP, exhibit a diurnal rhythm similar to those of bone resorption, but one that is less pronounced $^{(38)}$. PINP concentration was only measured at $8 \mathrm{~h}$, and was elevated in all groups at this time. After 3 months, bone turnover was significantly lower in the citrate-carbonate and $\mathrm{MCH}$ groups, reflected by reductions in both CTX and PINP concentrations. Lowered bone turnover is a wellestablished effect of Ca supplementation ${ }^{(21,39-41)}$.

Previous studies have compared the acute effects of different Ca preparations on serum Ca and PTH concentrations ${ }^{(6,21,24,30)}$, under the premise that larger increases in ionised Ca concentrations and reductions in PTH concentrations will translate into greater suppression of bone turnover. However, few have compared the long-term effects of different Ca preparations on markers of bone turnover. Despite the differences that we observed in the concentrations of ionised $\mathrm{Ca}$, phosphate and PTH between the $\mathrm{MCH}$ and citrate-carbonate groups, their effects on CTX and PINP concentrations were the same, acutely and after 3 months of treatment. Consistently, in longer trials, $\mathrm{MCH}$ has been as effective as calcium carbonate in slowing bone loss ${ }^{(42-44)}$. These findings suggest that the acute effects of Ca preparations on serum Ca concentrations might be disassociated from their longer-term effects on bone turnover.

Phosphate concentration was increased in the $\mathrm{MCH}$ group at $4 \mathrm{~h}$ compared with the control and citrate-carbonate groups. Participants allocated to the $\mathrm{MCH}$ treatment would have received an additional $0.5 \mathrm{~g}$ phosphate (based on a Ca:phosphate ratio in bone of 1.5) compared with those allocated to the other treatment groups. As higher concentrations of serum phosphate and the $\mathrm{Ca}$-phosphate product have been associated with increased CVD risk in the general population $^{(10,45-47)}$, this suggests that $\mathrm{MCH}$ might not provide a safer form of supplemental $\mathrm{Ca}$.

A weakness of the present study was the size of the dose of Ca studied. As in previous similar trials ${ }^{(5,6,24,26)}$, we examined 

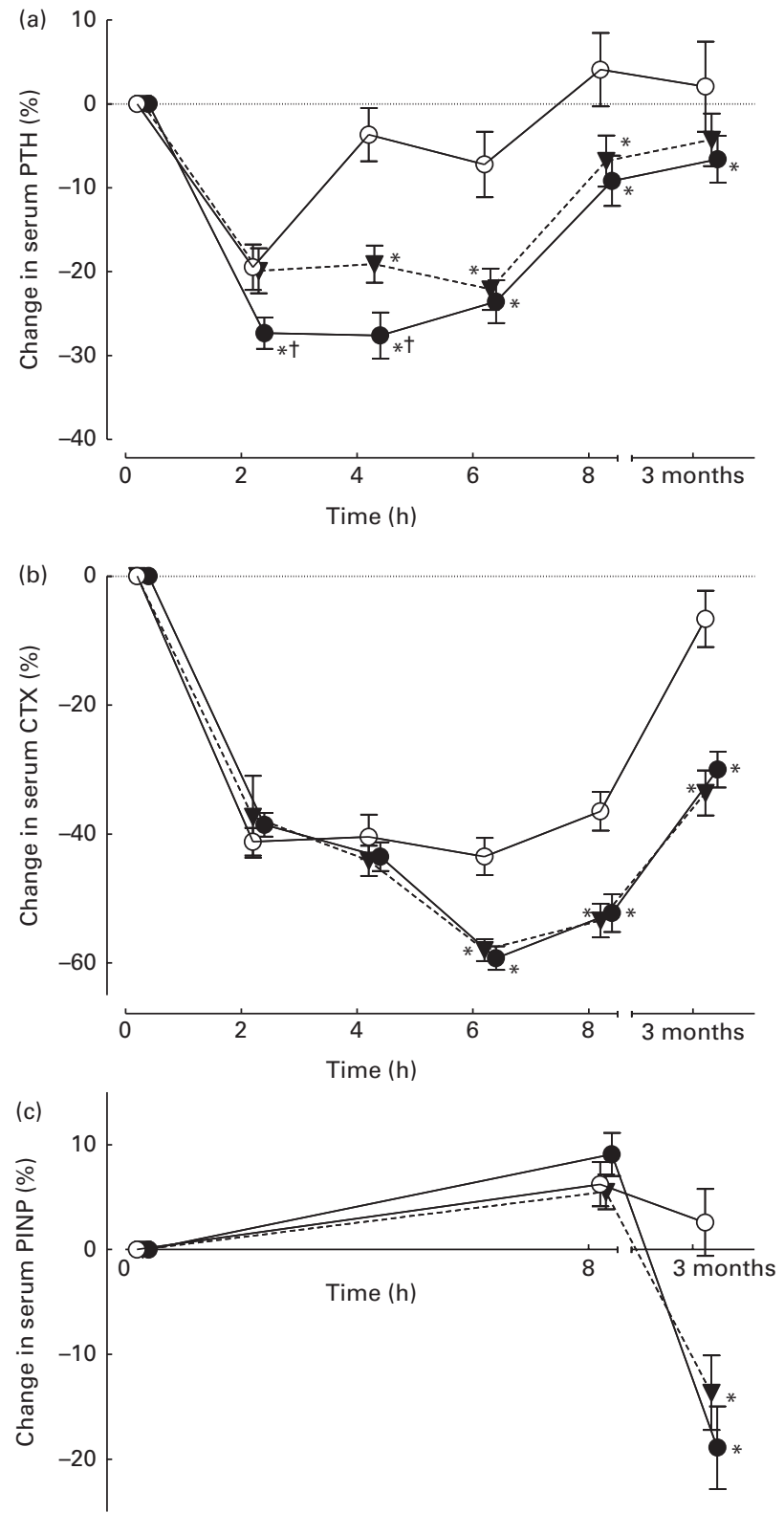

Fig. 5. Changes in serum (a) parathyroid hormone (PTH), (b) C-telopeptide (CTX) and (c) procollagen type-I N-terminal propeptide (PINP) concentrations over $8 \mathrm{~h}$ after the ingestion $1 \mathrm{~g}$ calcium as citrate or carbonate (citratecarbonate (-); $n$ 38), microcrystalline hydroxyapatite (MCH (- -); $n$ 39) or a placebo containing no calcium (control (-o); $n$ 20), and after 3 months of continuous supplementation. Values are means, with their standard errors represented by vertical bars. Changes in PTH (ANCOVA, treatment $\times$ time interaction, $P=0.004)$, CTX $(P=0.0002)$ and $\operatorname{PINP}(P<0.0001)$ concentrations up to 3 months differed significantly between the three groups. * Mean value was significantly different from that of the control group $(P<0.05)$. † Mean value was significantly different from that of the $\mathrm{MCH}$ group $(P<0.05)$.

the effects of $1 \mathrm{~g}$ Ca to maximise the differences between the preparations. However, $1 \mathrm{~g} / \mathrm{d}$ of supplemental $\mathrm{Ca}$ would commonly be taken in two doses of $0.5-0.6 \mathrm{~g}$, and daily changes in serum $\mathrm{Ca}$ concentrations may be smaller but possibly of a greater duration than that reported here. Most trials in the meta-analysis of $\mathrm{Ca}$ and cardiovascular events ${ }^{(27)}$ administered $1 \mathrm{~g} / \mathrm{d}$ of $\mathrm{Ca}$ in two divided doses, so any increase in cardiovascular risk may be related to such a dosing schedule.

In summary, conventional calcium citrate and carbonate supplements raised serum Ca concentrations for at least $8 \mathrm{~h}$, and this effect was not diminished with continuous use. $\mathrm{MCH}$ produced a smaller increase in ionised Ca concentrations, and a marginally smaller reduction in PTH concentrations, but had equivalent effects on bone turnover to the conventional $\mathrm{Ca}$ supplements. However, elevated concentrations of serum phosphate and the $\mathrm{Ca}$-phosphate product after the $\mathrm{MCH}$ treatment suggest that it may not provide a safer form of supplemental $\mathrm{Ca}$. Consuming $\mathrm{Ca}$ through dietary sources is currently the safest way for people to achieve their recommended $\mathrm{Ca}$ intake. For those unable to consume adequate $\mathrm{Ca}$ through diet alone, future research should aim at identifying the forms of supplemental $\mathrm{Ca}$ that release $\mathrm{Ca}$ into the blood slowly. The findings of the present study suggest that Ca preparations with smaller effects on serum Ca concentrations may still retain comparable efficacy in suppressing bone turnover.

\section{Acknowledgements}

The present study was supported by PharmaZen Limited and the Health Research Council of New Zealand. S. M. B. is the recipient of a University of Auckland Doctoral Scholarship.

The study sponsors had no role in the conduct of the study, the analysis of the samples and data, the interpretation of the findings or the writing of this article.

The authors' contributions are as follows: S. M. B. and I. R. R. formulated the research question and designed the study; S. M. B., A. S., L. H., M. E. H., O. A., B. M. and A. M. H. carried out the study; G. D. G., S. M. B. and I. R. R. analysed the data and S. M. B. and I. R. R. drafted the manuscript, which was critically revised by the co-authors.

None of the authors has any conflict of interest to declare.

\section{References}

1. Bolland MJ, Grey A, Gamble GD, et al. (2011) Calcium and vitamin D supplements and health outcomes: a reanalysis of the Women's Health Initiative (WHI) limited-access data set. Am J Clin Nutr 94, 1144-1149.

2. Li K, Kaaks R, Linseisen J, et al. (2012) Associations of dietary calcium intake and calcium supplementation with myocardial infarction and stroke risk and overall cardiovascular mortality in the Heidelberg cohort of the European Prospective Investigation into Cancer and Nutrition study (EPICHeidelberg). Heart 98, 920-925.

3. Xiao Q, Murphy RA, Houston DK, et al. (2013) Dietary and supplemental calcium intake and cardiovascular disease mortality: the National Institutes of Health-AARP diet and health study. JAMA Intern Med 173, 639-646.

4. Iso H, Stampfer MJ, Manson JE, et al. (1999) Prospective study of calcium, potassium, and magnesium intake and risk of stroke in women. Stroke 30, 1772-1779.

5. Karp HJ, Ketola ME \& Lamberg-Allardt CJ (2009) Acute effects of calcium carbonate, calcium citrate and potassium citrate on markers of calcium and bone metabolism in young women. Br J Nutr 102, 1341-1347. 
6. Heaney RP, Dowell MS, Bierman J, et al. (2001) Absorbability and cost effectiveness in calcium supplementation. J Am Coll Nutr 20, 239-246.

7. Karkkainen MU, Wiersma JW \& Lamberg-Allardt CJ (1997) Postprandial parathyroid hormone response to four calciumrich foodstuffs. Am J Clin Nutr 65, 1726-1730.

8. Slinin Y, Blackwell T, Ishani A, et al. (2011) Serum calcium, phosphorus and cardiovascular events in post-menopausal women. Int J Cardiol 149, 335-340.

9. Jorde R, Sundsfjord J, Fitzgerald P, et al. (1999) Serum calcium and cardiovascular risk factors and diseases: the Tromso study. Hypertension 34, 484-490.

10. Shin S, Kim KJ, Chang HJ, et al. (2012) Impact of serum calcium and phosphate on coronary atherosclerosis detected by cardiac computed tomography. Eur Heart $J$ 33, 2873-2881.

11. Reid IR \& Bolland MJ (2012) Risk factors: calcium supplements and cardiovascular risk. Nat Rev Cardiol 9, 497-498.

12. Bischoff-Ferrari HA, Kiel DP, Dawson-Hughes B, et al. (2009) Dietary calcium and serum 25-hydroxyvitamin D status in relation to BMD among U.S. adults. J Bone Miner Res 24, 935-942.

13. Warensjo E, Byberg L, Melhus H, et al. (2011) Dietary calcium intake and risk of fracture and osteoporosis: prospective longitudinal cohort study. BMJ 342, d1473.

14. Bauer DC (2013) Clinical practice. Calcium supplements and fracture prevention. $N$ Engl J Med 369, 1537-1543.

15. Manson JE \& Bassuk SS (2014) Calcium supplements: do they help or harm? Menopause 21, 106-108.

16. Ma J, Johns RA \& Stafford RS (2007) Americans are not meeting current calcium recommendations. Am J Clin Nutr 85, 1361-1366.

17. Pasco JA, Sanders KM, Henry MJ, et al. (2000) Calcium intakes among Australian women: Geelong Osteoporosis Study. Aust N Z J Med 30, 21-27.

18. University of Otago and Ministry of Health (2011) A Focus on Nutrition: Key Findings of the 2008/09 New Zealand Adult Nutrition Survey. Wellington: Ministry of Health.

19. Martins I, Dantas A, Guiomar S, et al. (2002) Vitamin and mineral intakes in elderly. J Nutr Health Aging 6, 63-65.

20. Lovelace HY \& Barr SI (2005) Diagnosis, symptoms, and calcium intakes of individuals with self-reported lactose intolerance. J Am Coll Nutr 24, 51-57.

21. Reid IR, Schooler BA, Hannan SF, et al. (1986) The acute biochemical effects of four proprietary calcium preparations. Aust N Z J Med 16, 193-197.

22. Tang BM, Eslick GD, Nowson C, et al. (2007) Use of calcium or calcium in combination with vitamin D supplementation to prevent fractures and bone loss in people aged 50 years and older: a meta-analysis. Lancet 370, 657-666.

23. Angus RM, Sambrook PN, Pocock NA, et al. (1989) A simple method for assessing calcium intake in Caucasian women. J Am Diet Assoc 89, 209-214.

24. Deroisy R, Zartarian M, Meurmans L, et al. (1997) Acute changes in serum calcium and parathyroid hormone circulating levels induced by the oral intake of five currently available calcium salts in healthy male volunteers. Clin Rheumatol 16, 249-253.

25. Horowitz M, Wishart JM, Goh D, et al. (1994) Oral calcium suppresses biochemical markers of bone resorption in normal men. Am J Clin Nutr 60, 965-968.

26. Thomas SD, Need AG, Tucker G, et al. (2008) Suppression of parathyroid hormone and bone resorption by calcium carbonate and calcium citrate in postmenopausal women. Calcif Tissue Int 83, 81-84.
27. Bolland MJ, Grey A, Avenell A, et al. (2011) Calcium supplements with or without vitamin D and risk of cardiovascular events: reanalysis of the Women's Health Initiative limited access dataset and meta-analysis. BMJ 342, d2040.

28. Buclin T, Jacquet AF \& Burckhardt $\mathrm{P}$ (1986) Intestinal absorption of calcium gluconate and oseine-mineral complex: an evaluation by conventional analyses. Schweiz Med Wochenschr 116, 1780-1783.

29. Nicar MJ \& Pak CY (1985) Calcium bioavailability from calcium carbonate and calcium citrate. J Clin Endocrinol Metab 61, 391-393.

30. Harvey JA, Zobitz MM \& Pak CY (1988) Dose dependency of calcium absorption: a comparison of calcium carbonate and calcium citrate. J Bone Miner Res 3, 253-258.

31. Recker RR (1985) Calcium absorption and achlorhydria. $N$ Engl J Med 313, 70-73.

32. Heaney RP, Recker RR \& Weaver CM (1990) Absorbability of calcium sources: the limited role of solubility. Calcif Tissue Int 46, 300-304.

33. Ekman M, Reizenstein P, Teigen SW, et al. (1991) Comparative absorption of calcium from carbonate tablets, lactogluconate/carbonate effervescent tablet, and chloride solution. Bone 12, 93-97.

34. el-Hajj Fuleihan G, Klerman EB, Brown EN, et al. (1997) The parathyroid hormone circadian rhythm is truly endogenous - a general clinical research center study. J Clin Endocrinol Metab 82, 281-286.

35. Greenspan SL, Dresner-Pollak R, Parker RA, et al. (1997) Diurnal variation of bone mineral turnover in elderly men and women. Calcif Tissue Int 60, 419-423.

36. Wichers M, Schmidt E, Bidlingmaier F, et al. (1999) Diurnal rhythm of CrossLaps in human serum. Clin Chem $\mathbf{4 5}$, 1858-1860.

37. Qvist P, Christgau S, Pedersen BJ, et al. (2002) Circadian variation in the serum concentration of C-terminal telopeptide of type I collagen (serum CTx): effects of gender, age, menopausal status, posture, daylight, serum cortisol, and fasting. Bone 31, 57-61.

38. Ahmad AM, Hopkins MT, Fraser WD, et al. (2003) Parathyroid hormone secretory pattern, circulating activity, and effect on bone turnover in adult growth hormone deficiency. Bone 32, 170-179.

39. Riggs BL, O'Fallon WM, Muhs J, et al. (1998) Long-term effects of calcium supplementation on serum parathyroid hormone level, bone turnover, and bone loss in elderly women. J Bone Miner Res 13, 168-174.

40. Reid IR, Mason B, Horne A, et al. (2006) Randomized controlled trial of calcium in healthy older women. $A m \mathrm{~J}$ Med 119, 777-785.

41. Reid IR, Ames R, Mason B, et al. (2008) Randomized controlled trial of calcium supplementation in healthy, nonosteoporotic, older men. Arch Intern Med 168, 2276-2282.

42. Ruegsegger P, Keller A \& Dambacher MA (1995) Comparison of the treatment effects of ossein-hydroxyapatite compound and calcium carbonate in osteoporotic females. Osteoporos Int 5, 30-34.

43. Pelayo I, Haya J, De la Cruz JJ, et al. (2008) Raloxifene plus ossein-hydroxyapatite compound versus raloxifene plus calcium carbonate to control bone loss in postmenopausal women: a randomized trial. Menopause 15, 1132-1138.

44. Ciria-Recasens M, Blanch-Rubio J, Coll-Batet M, et al. (2011) Comparison of the effects of ossein-hydroxyapatite complex and calcium carbonate on bone metabolism in women with 
senile osteoporosis: a randomized, open-label, parallelgroup, controlled, prospective study. Clin Drug Investig 31, 817-824.

45. Foley RN, Collins AJ, Ishani A, et al. (2008) Calciumphosphate levels and cardiovascular disease in communitydwelling adults: the Atherosclerosis Risk in Communities (ARIC) Study. Am Heart J 156, 556-563.
46. Foley RN, Collins AJ, Herzog CA, et al. (2009) Serum phosphorus levels associate with coronary atherosclerosis in young adults. J Am Soc Nephrol 20, 397-404.

47. Dhingra R, Sullivan LM, Fox CS, et al. (2007) Relations of serum phosphorus and calcium levels to the incidence of cardiovascular disease in the community. Arch Intern Med 167, 879-885. 